\title{
Quantitative evaluation of the nexus between water and energy in China
}

\author{
HE Guohua $^{1, \mathrm{a}^{*}}$, Li Xiaoling ${ }^{2}$, JIANG Shan ${ }^{1}$, ZHU Yongnan ${ }^{1}$, HE Fan ${ }^{1}$, LI Haihong ${ }^{1}$ \\ ${ }^{1}$ State Key Laboratory of Simulation and Regulation of Water Cycle in River Basin, China Institute of Water Resources and Hydropower \\ Research, Beijing 100038, China \\ ${ }^{2}$ College of Civil Engineering and Architecture, Guangxi University, Nanning, Guangxi 530004, China
}

\begin{abstract}
This paper takes each province and region as the research object and 2017 as the research period, and the energy consumption of China's social water cycle process was analyzed. The results showed that the total power consumption of China's social water cycle process was 1082.81 billion $\mathrm{kWh}$, accounting for $17.2 \%$ of the total power consumption of China's society in 2017. Terminal water consumption is the biggest energy consumption. Based on the calculated results, this study puts forward relevant suggestions for realizing energy-water coordinated security.
\end{abstract}

\section{Introduction}

According to the research results of the IEA, the energy consumed in the water cycle of the global society is as high as 2833.4 billion $\mathrm{kWh}$, accounting for about $2.5 \%$ of the total energy consumption of the global primary energy 1. On a global scale, energy and water resources have become important constraints to each other's sustainable development. In the context of the substantial increase in global resource demand, only by taking energy and water resources as a research body, enhancing the coordination, rational allocation and constantly adjusting human behavior, can the green development of the region be realized 2 .

Due to the shortage of energy and water resources and the significant spatial difference between them, China has become a hot spot in the research on the global energy and water nexus. Many scholars have carried out quantitative research on the energy-water nexus in typical areas such as the Yellow River basin 3, Beijing 4 and the national scale 5-7. According to the national comprehensive plan on water resources, China's total water use will increase to 696 billion $\mathrm{m}^{3}$ in 2030, among which the supply of energyintensive water resources such as external water diversion, renewable water and desalinated seawater will increase substantially, which will also lead to increased energy competition between the water conservancy industry and other industries 8. According to the research results of Jiang Shan et al. 9, at present, China's energy and water problems are mainly faced with three challenges: 1) rapidly increasing consumption demand of energy and water; 2) the optimal selection of energy-intensive water sources and water-intensive energy sources; 3) the coupling and coordination of energy-water cross-sector policy making.

The quantitative identification of the relationship between energy and water is the basis of China's economic, social and ecological sustainable development. But at present, the academic circles mainly carry out research on the framework concept of this bond, and there are few quantitative researches in the whole country. Based on this, this article takes the provincial administrative region for the study of the smallest unit, choose 2017 as the current level year. The electricity consumption in the whole process of water cycle is quantitatively analyzed, and based on the research results, the policy suggestions for the coordinated development of energy and water in China are put forward, so as to provide references for the sustainable development of economy, resources and environment in China.

\section{Methods and data}

\subsection{Calculation of energy consumption of the whole process of social water cycle}

Social water cycle energy consumption refers to the energy consumption associated with water intake, water production, water transmission and distribution, water use, drainage and sewage reuse. The purpose of calculating social water cycle energy consumption is to improve the collaborative management ability of water resources and energy.

\subsubsection{Calculation of energy consumption during water intake}

(1) Surface water intake

The process of water diversion is mostly completed by artesian flow and requires less energy. Therefore, the energy consumption is neglected in this paper. The water

\footnotetext{
a Corresponding author: He Guohua (hegh@iwh.com)
} 
lifting project and water transfer project rely on the electric pump for extraction, and the energy consumption calculation formula is shown in formula (1) and formula (2).

$$
\begin{aligned}
& W_{1}=\frac{m g h}{3.6 \times 10^{6} \times \varepsilon} \\
& W_{\mathrm{t}}=L \times m^{2} \times n^{2} \frac{\left(b+2 h \sqrt{1+c^{2}}\right)^{\frac{4}{3}}}{[(b+c h) \times h]^{\frac{10}{3}}}
\end{aligned}
$$

Where, $W_{1}$ and $W_{t}$ represents the energy consumption of the water lifting project and the water transfer project respectively, $\mathrm{kWh} ; m$ is water quality, $\mathrm{kg}$; $g$ is the acceleration of gravity, N/kg; $h$ is the lifting height of water body, $\mathrm{m} ; \varepsilon$ is the efficiency of the pumping station, diesel pump is generally $15 \%$, and electromechanical pump is generally $40 \% 10 . L$ is the length of water delivery, $\mathrm{m} ; n$ is the roughness rate of canal system; $b$ is the canal system bottom width, $\mathrm{m} ; h$ is the water surface height of the channel, $\mathrm{m} ; c$ is the slope coefficient of canal system.

(2)Groundwater extraction

The calculation formula of the energy consumption of groundwater is as follows:

$$
W_{g}=\frac{m g h}{3.6 \times 10^{6} \times \varepsilon \times(1-\theta)}
$$

Where, $W_{\mathrm{g}}$ represents the energy consumption of groundwater to carry water, $\mathrm{kWh}$. $\theta$ is the head loss in the process of water extraction, which is related to the type of pump station and the height of water extraction. In this study, it is assumed that is 5\% 11 .

(3)Energy consumption of sea water desalination

Seawater desalination projects in China are mainly distributed in coastal areas such as Tianjin, Liaoning and Hebei, with the current annual desalination scale of 434 million $\mathrm{m}^{3}$. Currently, reverse osmosis method is mainly used in seawater desalination in China, and the average unit energy consumption is $6.8 \mathrm{kWh} / \mathrm{m}^{3} 12$.

\subsubsection{Calculation of energy consumption during water production process}

The energy consumption of water produced by water plants in various provinces in China comes from the Statistical yearbook of urban water supply in 201713 .

\subsubsection{Calculation of energy consumption during water transmission and distribution process}

The energy consumption per unit of water transmission and distribution in different provinces is different, and the data of water transmission and distribution energy consumption in each region is from the 2017 Statistical yearbook of urban water supply 13.

\subsubsection{Calculation of energy consumption during water use process}

Considering that the energy consumption of the agricultural sector water use is mainly concentrated in the groundwater water carrying process, and the energy consumption in the water using process is less, this study does not consider the energy consumption of agricultural water use separately. Since the energy consumption of ecological water use process is negligible, this study only calculates the energy consumption of domestic and industrial water use.

(1)Domestic water use

Domestic water consumption is mainly divided into heating energy consumption and mechanical energy consumption. The calculation formulas of heating energy consumption and mechanical energy consumption of domestic water use are shown in formula (4) and (5) respectively

$$
\begin{aligned}
& e_{h}=\frac{\left[V \times \rho \times C \times\left(T_{t}-T_{i}\right)\right] / u+E}{Q \times 3.6 \times 10^{3}} \\
& e_{m}=\frac{B \times D \times 3600}{Q \times 3.6 \times 10^{3}}
\end{aligned}
$$

Where, $e_{h}$ and $e_{m}$ respectively refers to the heating and mechanical energy consumption in the process of domestic water consumption, $\mathrm{kWh} / \mathrm{m}^{3} ; V$ is the storage volume of the water heater, $\mathrm{L}$; $\rho$ is the density of water, $\mathrm{kg} / \mathrm{L} ; C$ is the specific heat capacity of water, $\mathrm{kJ} /\left(\mathrm{kg} \cdot{ }^{\circ} \mathrm{C}\right)$; $T_{t}$ and $T_{i}$ are respectively the temperature of the heater under constant temperature and air temperature, ${ }^{\circ} \mathrm{C} ; \mu$ is the energy consumption coefficient of the heater; $E$ is standby heat loss, $\mathrm{kJ} ; Q$ is water consumption in the heating process, $\mathrm{m}^{3} ; B$ is the rated power of a type of washing machine, $\mathrm{kWh} / \mathrm{kg} ; D$ is the rated washing capacity of this type of washing machine, $\mathrm{kg}$.

(2)Industry water use

According to the research results of He et al. ${ }^{[4]}$, the energy consumption of industrial water mainly focuses on the heating energy consumption. The calculation formula of heating energy consumption is as follows:

$$
e_{I}=\frac{C \times m \times\left(T_{h}-T_{i}\right)}{3.6 \times 10^{6} \times \gamma}
$$

Where, $e_{I}$ is energy consumption for boiler heating, $\mathrm{kWh} / \mathrm{m}^{3} ; T_{h}$ is the temperature to which industrial water needs to be heated, ${ }^{\circ} \mathrm{C} ; \gamma$ is boiler heat efficiency, average of $75 \%$.

\subsubsection{Calculation of energy consumption during drainage process}

In 2017, China's sewage discharge was 75.6 billion $\mathrm{m}^{3}$, of which 45.3 billion $\mathrm{m}^{3}$ was treated. The energy consumption data of China's sewage treatment plants in 2017 came from the Statistical yearbook of urban drainage 14.

\subsubsection{Calculation of energy consumption during drainage process regenerated water treatment process}

Due to the complexity and different reuse purposes of sewage components, the treatment processes of reclaimed water vary greatly. Therefore, the national average was used to calculate the energy consumption of sewage reuse process. According to the 2017 statistical yearbook of urban drainage 14, the national average energy consumption per unit of renewable water treatment is $0.82 \mathrm{kWh} / \mathrm{m}^{3}$. 


\section{Results and discussion}

\subsection{Analysis of energy consumption of the whole process of social water cycle}

In 2017 , the total amount of electricity consumed during the water cycle in China was 1082.81 billion $\mathrm{kWh}$, accounting for $17.2 \%$ of the total amount of electricity consumed in the whole society. According to figure 1, the water-using process is the link that consumes the most water in the social water cycle, in which the energy consumption of industrial water is 570.11 billion $\mathrm{kWh}$, and that of domestic water is $3833.1 \mathrm{kWh}$, accounting for $52.7 \%$ and $35.4 \%$ of the total energy consumption of the whole water cycle respectively. Since the 21 st century, the industrial water and domestic water are the industries with a rapid increase in China's water consumption. With the further expansion of industry and population in the future,
China's industrial and domestic water consumption and energy consumption may further increase. Water intake is the second major energy consumption link in the water cycle, consuming 84.08 billion $\mathrm{kWh}$ of electricity, accounting for $7.8 \%$ of the total energy consumption of the water cycle. The processes of water supply, conveyance and drainage consume less energy, accounting for $1.1 \%, 1.4 \%$ and $1.1 \%$ of the total energy consumption of the whole society respectively. In terms of total amount, the energy consumption of reclaimed water treatment is less than that of surface water and groundwater development. However, from the point of view of unit energy consumption, the energy consumption of single water of reclaimed water $(0.82 \mathrm{kWh} / \mathrm{m})$ is higher than that of surface water $(0.15 \mathrm{kWh} / \mathrm{m})$ and groundwater $(0.32 \mathrm{kWh} / \mathrm{m})$. The extensive use of renewable water can effectively relieve the pressure of water resources in our country, but it means that we have to pay more energy costs.

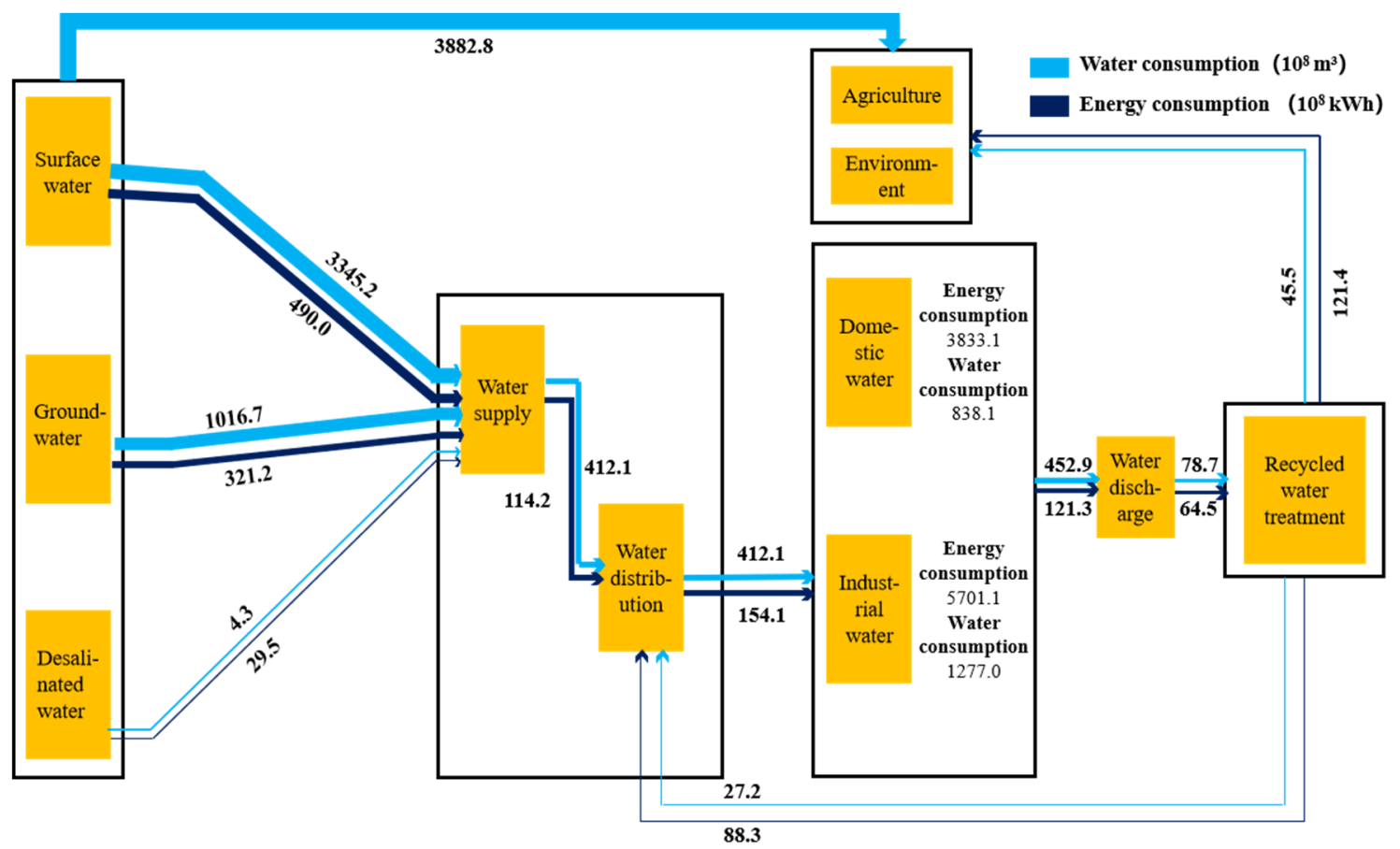

Figure 1 Energy consumption in social water cycle progress in China in 2017

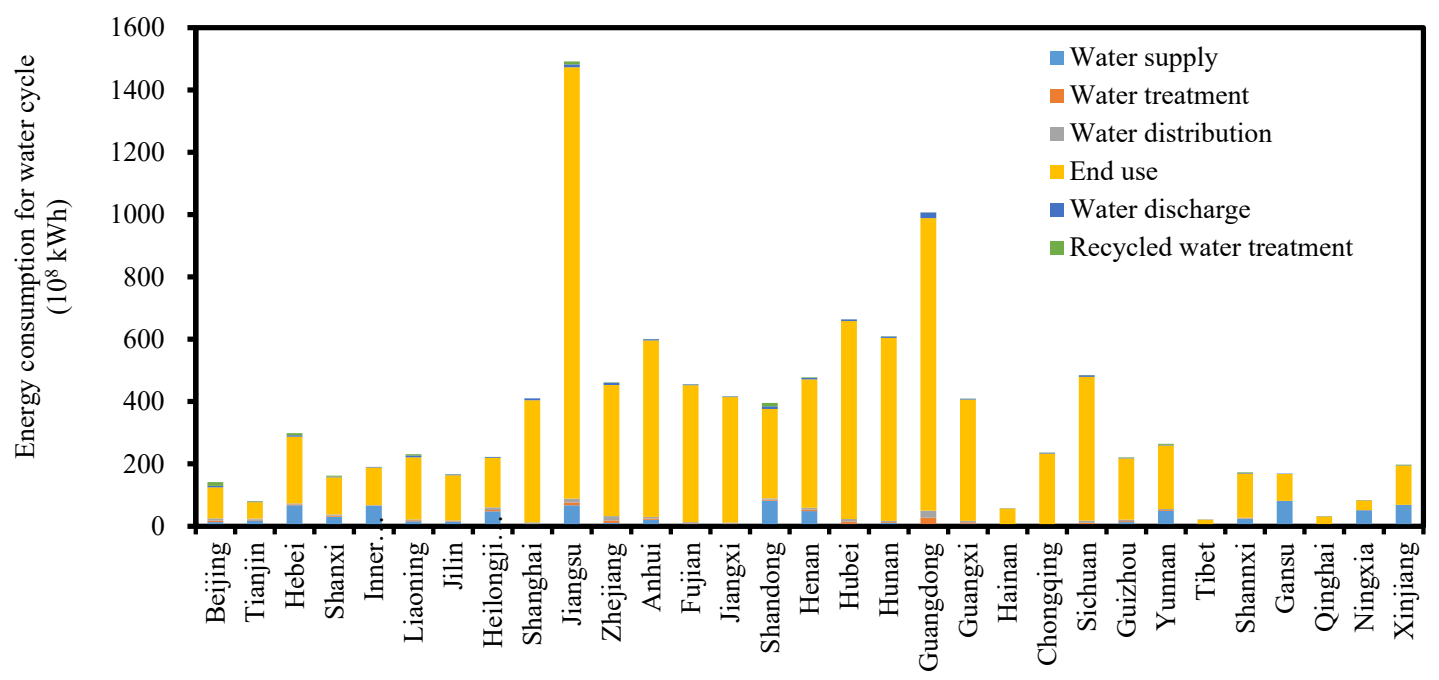

Figure 2 Energy consumption in water cycle process in different provinces in 2017 


\subsection{The spatial difference of energy consumption in the social water cycle}

Due to the differences of water resources background conditions and industrial structure, the energy consumption of water cycle varies greatly in different regions of China. Jiangsu is the province with the largest amount of water consumption in China, accounting for $9.8 \%$ of China's total water consumption in 2017. Meanwhile, Jiangsu is also the province with the highest energy consumption of water cycle in the society. Its total energy consumption in 2017 reached 149.13 billion $\mathrm{kWh}$, accounting for $13.8 \%$ of the country's total energy consumption. Xizang is the province that consumes the least amount of water in the society. In 2017, its total energy consumption was 2.111 billion $\mathrm{kWh}$, only accounting for $0.2 \%$ of the national total and $1 / 7$ th of that of Jiangsu. From the perspective of zoning, due to the difference in water use scale between the north and south, the water cycle energy consumption of the southern provinces is generally higher than that of the north. In 2017 , the total water cycle energy consumption of the north and south was 8682.4 billion $\mathrm{kWh}$ and 214.58 billion $\mathrm{kWh}$, respectively, with the north only one quarter of that of the south. In general, whether in the south or the north, the terminal water use process is the most energy consuming part of the water cycle in each region. Considering the consistency of the consumption of water resources and energy in the process of water use, the implementation of water-saving measures in the water use terminal can achieve the win-win goal of water saving and energy saving.

\section{Conclusion and suggestion}

\subsection{Conclusion}

In 2017, the total amount of electricity consumed in China's social water cycle was 1082.81 billion $\mathrm{kWh}$, accounting for $17.2 \%$ of the total amount of electricity consumed in China in that year. Terminal water consumption is the biggest energy consumption, accounting for $88.1 \%$ of the total water consumption. From the perspective of zoning, Jiangsu and Xizang are the provinces that consume the most and the least water circulation in China, respectively, with energy consumption of 1491.3 and 2111 million kWh in 2017.

\subsection{Suggestion}

(1) Terminal water consumption is the biggest energy consuming link in the process of social water circulation. Considering the consistency of the process of water and energy utilization in this link, efficient water saving at the water use side can effectively improve the utilization efficiency of water and energy and achieve the dual purpose of water saving and energy saving.

(2) The water-energy system management concept should be established based on the development characteristics and resource endowment conditions of different regions, the energy influence should be considered in the process of water resources development, and the water resources restriction should be considered in the process of energy development, so as to realize the coordinated security of water resources and energy in China.

\section{Acknowledgments}

This work was funded by the National Youth Science Foundation (51809282).

\section{References}

1. Liu Y, Hejazi M, Kyle P, et al. Global and regional evaluation of energy for water. J. Environmental science \& technology, 50(17): 9736-9745 (2016).

2. Wang S X. The limit and cycle of energy and mineral resources consumption growth. J. World Nonferrous Metals, 5: 254-256 (2018).

3. Xiang X Z, Jesper S, Jia S F. Will the energy industry drain the water used for agricultural irrigation in the Yellow River basin? J. International Journal of Water Resources Development, 33(1): 69-80 (2017).

4. He G H, Zhao Y, Wang J H, et al. The effects of urban water cycle on energy consumption in Beijing, China. J. Journal of Geographical Sciences, 29(6): 959-970 (2019).

5. Xiang X Z, Jia S F. Estimation and Trend Analysis of Water Demand of Energy Industry in China. J. Journal of Natural Resources, 31(1): 114-123 (2016).

6. Xiang X Z, Jia S F. (2019) China's water-energy nexus: Assessment of water-related energy use. J. Resources, Conservation and Recycling, 144: 32-38 (2019).

7. He G H, Zhao Y, Jiang S, et al. Impact of virtual water transfer among electric sub-grids on China's water sustainable developments in 2016, 2030, and 2050. J. Journal of Cleaner Production, 229: 1546-1559 (2019).

8. Peng S M, Wang H, Zhang X H. Research on the development demand and water resources control strategy of the middle and upper reaches of the Yellow River. J. China Water Resources, 21: 28-31 (2011).

9. Jiang S, Zhao Y, Shang Y Z, et al. Balancing Development of Thermal Power with Available Water Resources in Major Coal Bases of China. J. Water Resources and Power, 34(11): 40-43 (2016).

10. Wang J X, Rothausen S G S A, Conway D, et al. China's water-energy nexus: greenhouse-gas emissions from groundwater use for agriculture. J. Environmental Research Letters, 7(1): 14035-14044 (2012).

11. Jiang S. Analysis and Coupling of Water-Energy Nexus. Beijing: China Institute of Water Resources and Hydropower Research (2017).

12. National Research Council. Desalination: a national perspective (2008).

13. China Urban Water Association. Urban Water Supply 
Statistical Yearbook in 2017 (2018).

14. China Urban Water Association. Urban Water

Drainage Statistical Yearbook in 2017 (2018). 